\title{
Preliminary evaluation of a natural surfactant extracted from Myrtus communis plant for enhancing oil recovery from carbonate oil reservoirs
}

\author{
Iman Nowrouzi ${ }^{1}$. Amir H. Mohammadi ${ }^{1}\left[\right.$. Abbas Khaksar Manshad ${ }^{2}$
}

Received: 8 July 2021 / Accepted: 13 October 2021 / Published online: 21 October 2021

(c) The Author(s) 2021

\begin{abstract}
Surfactants are among the materials used to improve water properties for injection into oil reservoirs, and reduce injection phase and crude oil interfacial tension (IFT). Recently, the interest in the use of natural surfactants has increased and is constantly on the rise to solve some challenges of using chemical surfactants such as incompatibility with the environment and the high cost. In this study, we have used aqueous extract of powdered leaf of Myrtus communis as an available source of natural surfactant. The extracted surfactant was characterized by TGA, ${ }^{1} \mathrm{H}$ NMR and FTIR techniques. The surfactant efficiency was demonstrated by performing some experiments including IFT and injection of chemical slug and surfactant into carbonate plugs. The surfactant adsorption on carbonate rock was also studied. It was observed that this natural surfactant can reduce IFT to $0.861 \mathrm{mN} / \mathrm{m}$ at surfactant critical micelle concentration (CMC) of $5000 \mathrm{ppm}$. This minimum IFT was further reduced at optimum salinity and alkali. Finally, an increase of $14.3 \%$ oil recovery by surfactant flooding and $16.4 \%$ oil recovery by ASP slug injection containing $\mathrm{NaOH}$ alkali and partially hydrolyzed polyacrylamide (PHPA) polymer with $0.5 \mathrm{PV}$ volume from carbonate plugs was achieved.
\end{abstract}

Keywords Myrtus communis · Saponin · Interfacial tension · Adsorption · Surfactant flooding $\cdot$ Natural surfactant

\section{Introduction}

In a chemical water injection program, what is most important is the management of additives in aqueous phase to enhance oil recovery. The most advanced type of management, and engineering of soluble ions in injected water is known as the "Smart Water Technique" (Manshad et al. 2016). In general, it can be said that the use of additives with optimal and adjusted concentrations is performed to control the surface properties of rock and fluid to modify the effective factors on enhanced oil recovery (EOR), such as

Amir H. Mohammadi

amir_h_mohammadi@yahoo.com

$\triangle$ Abbas Khaksar Manshad

khaksar@put.ac.ir

1 Discipline of Chemical Engineering, School of Engineering, University of KwaZulu-Natal, Howard College Campus, King George V Avenue, Durban 4041, South Africa

2 Department of Petroleum Engineering, Abadan Faculty of Petroleum Engineering, Petroleum University of Technology (PUT), Abadan, Iran interfacial tension and wettability, and subsequently capillary forces. Surfactants are the most commonly used additive chemicals in injection water, which are mostly used for IFT reduction (Pu et al. 2018). They also have beneficial effects on the formation of emulsions and rock wettability. However, reducing water-oil IFT and adsorption on the rock are among the most important influences on the performance of surfactants in chemical EOR. Reducing interfacial tension by reducing the capillary pressures causes the remaining oil in the porous space to move. In addition, by forming emulsions of water and oil, larger droplets of oil turn into fine droplets which can better move in the cavities inside the rock (Nguyen et al. 2019). However, the surfactant adsorption on the rock wastes this material. Therefore, investigation of adsorption is essential before conducting any surfactant injection study. Recently, the interest in the use of some surfactants is on the rise. Majidaie et al. (2012) prepared a non-petrochemical surfactant. They increased the oil recovery by $11.11 \%$ by flooding tests of the surfactant solution. The surfactant tested reduced the interfacial tension to $0.19 \mathrm{mN} / \mathrm{m}$. Khayati et al. (2020) showed that pure saponin could reduce the interfacial tension of water and kerosene 
by $66.98-77.31 \%$ and change the wettability of sandstone to hydrophilicity. Saxena et al. (2019a) studied a Madhuca longifolia (Mahua) oil-based surfactant and could achieve an ultra-low IFT. They also obtained an ultra-low IFT by a surfactant of soap nut. The sandstone wettability was altered to water-wet, and oil recovery of $30 \%$ was increased by an SP slug injection (Saxena et al. 2019b). Alsabagh et al. (2021) tested non-ionic surfactants synthesized from cooking oil wastes. The interfacial tension decreased to $0.06 \mathrm{mN} / \mathrm{m}$ and oil recovery by surfactant flooding reached $54.2 \%$. Kiani et al. (2019) investigated a novel anionic surfactant namely iC18S (FO-180) for EOR at different salinities. Severe IFT reduction and wettability improvement and $72 \%$ of total oil production by flooding in a glass micromodel were reported in their research. Tay et al. (2019) reduced IFT to $3.5-4.0 \mathrm{mN} / \mathrm{m}$ and increased oil production using an Internal Ketone Sulfonates surfactant. Ganie et al. (2019) examined a mixture of different ratios of lignin-based surfactants. In addition to IFT reduction of $0.7-0.8 \mathrm{mN} / \mathrm{m}$ and recovery factor increasing of $19 \%$, they obtained a formula of concentration as the best mixture. Najimi et al. (2019) used ionic liquid-based surfactants as IFT reducing agents. They obtained an IFT reduction of $70 \%$ at very high salinity. Manshad et al. (2017) used some ionic liquids for IFT reduction. They optimized IFT and increased oil recovery by the ionic liquid injection. Kumar and Mandal (2018) showed the relationship of carbon number of zwitterionic surfactant tail and IFT reduction. They observed a further reduction in IFT when the carbon number of the tail of the surfactant is on the rise. Madani et al. (2019) used a surfactant with the base of amino acid and obtained a lower IFT and improved the wettability of carbonate and sandstone and total oil production of $57.26 \%$. Pal et al. (2018a, 2019) extracted new Gemini surfactants from Sunflower for EOR. The surfactant was able to drastically reduce IFT. Further, Pal et al. (2018b) prepared surfactant from coconut oil and achieved an ultra-low IFT and altered the quartz wettability. They finally increased oil production by $20.05 \%$. Pal et al. (2018c) synthesized and investigated cationic Gemini surfactants for EOR. The IFT reached $10^{-2}-10^{-3} \mathrm{mN} / \mathrm{m}$, and the wettability altered from hydrophobic to intermediate in their evaluation. Besides, a recovery factor of $29-34 \%$ was reported by surfactant flooding in sand-pack. Pillai et al. (2018) used ionic liquids with the basis of imidazolium and showed that the ionic liquids can work at harsh conditions of the reservoir in terms of salinity and temperature. They increased oil recovery by about $32 \%$ using a chemical slug injection. Rostami et al. (2017) reduced the IFT and modified wettability using a Lysine Derivative surfactant. They also achieved an increase of $12 \%$ in oil production by surfactant injection. Yan et al. (2019) showed that the Double-Chain Single-Head surfactants could reduce IFT to ultra-low values. Most of the plant's surfactants, due to the presence of saponins in their composition, have a good surface activity and exhibit the ability to create foam and form emulsions with oil (Bachari et al. 2019). Myrtus communis leaves extract has these properties in addition to being very affordable, especially in oilrich countries. In this study, we have studied the extracted saponin from Myrtus communis as a natural surfactant. Myrtus communis is an evergreen plant of the Mirtaceae family that grows throughout the Mediterranean, Middle East, Iran, and parts of Europe, which has many types (Ghannadi and Dezfuly 2011). FTIR, ${ }^{1}$ H NMR and TGA techniques were used for characterization and evaluation of the thermal stability of the natural surfactant. IFT experiments and surfactant and alkali-surfactant-polymer (ASP) slug injection into carbonate plugs were also done to demonstrate the surfactant application in EOR process. In addition, the impacts of $\mathrm{CaCl}_{2}, \mathrm{NaCl}, \mathrm{Na}_{2} \mathrm{SO}_{4}, \mathrm{~K}_{2} \mathrm{SO}_{4}, \mathrm{KI}, \mathrm{KCl}, \mathrm{MgCl}_{2}$ and $\mathrm{MgSO}_{4}$ salinities and $\mathrm{NaOH}$ alkalinity on the surfactant efficiency in IFT reduction were investigated, and the surfactant adsorption onto carbonate rock and the $\mathrm{pH}$ of the surfactant solutions were studied.
Table 1 The crude oil information

Table 2 The composition of formation water

每

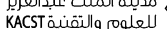

\begin{tabular}{lllllllllllllll}
\hline Component & $\mathrm{C}_{2}$ & $\mathrm{C}_{3}$ & $\mathrm{iC}_{4}$ & $\mathrm{nC}_{4}$ & $\mathrm{iC}_{5}$ & $\mathrm{nC}_{5}$ & $\mathrm{C}_{6}$ & $\mathrm{C}_{7}$ & $\mathrm{C}_{8}$ & $\mathrm{C}_{9}$ & $\mathrm{C}_{10}$ & $\mathrm{C}_{11}$ & $\mathrm{C}_{12}{ }^{+}$ & Total \\
\hline Percent, molar & 0.08 & 0.73 & 0.72 & 2.22 & 1.10 & 1.10 & 8.66 & 9.32 & 6.60 & 7.14 & 5.36 & 5.01 & 51.96 & 100.00 \\
$M_{w}=247 \mathrm{~g} / \mathrm{gmol}$ & & & & & & & & & & & & & \\
$\mathrm{C}_{12}^{+} M_{w}=380 \mathrm{~g} / \mathrm{gmol}$ & & & & & & & & & & & & \\
$\mathrm{C}^{12+} \mathrm{Sp}$. Gr $\left(@ 15.55^{\circ} \mathrm{C}\right)=0.9369$ & & & & & & & & & & &
\end{tabular}

\begin{tabular}{llllllllll}
\hline Component & T.D.S & $\mathrm{K}^{+}$ & $\mathrm{Mg}^{2+}$ & $\mathrm{Fe}_{2}{ }^{+}$ & $\mathrm{HCO}_{3}{ }^{-}$ & $\mathrm{Ca}^{2+}$ & $\mathrm{Na}^{+}$ & $\mathrm{SO}_{4}{ }^{2-}$ & $\mathrm{Cl}^{-}$ \\
\hline Concentration, ppm & 74,000 & 180 & 1700 & 30 & 210 & 3500 & 25,300 & 220 & 39,050 \\
\hline
\end{tabular}




\section{Experimental section}

\section{Materials}

Dead oil with an API gravity of 31.14 and an acidity equal to $3.7 \mathrm{mg} \mathrm{KOH} / \mathrm{g}$ and formation water of Gachsaran reservoir located in southwest of Iran were used. The crude oil and formation water components are reported in Tables 1 and 2. $\mathrm{KCl}, \mathrm{NaCl}, \mathrm{CaCl}_{2}, \mathrm{MgCl}_{2}, \mathrm{Na}_{2} \mathrm{SO}_{4}$, $\mathrm{MgSO}_{4}, \mathrm{~K}_{2} \mathrm{SO}_{4}$ and $\mathrm{KI}$ salts and $\mathrm{NaOH}$ alkali and partially hydrolyzed polyacrylamide (PHPA) polymer from MP Biomedicals Company of the Netherlands with the given specifications in Table 3 were used. Rock samples taken from the Asmari carbonate formation outcrop in Khuzestan (Iran) were used. The carbonate rock contained $61 \%$ dolomite and 39\% calcite. Figure 1 shows the XRD and SEM analyses of the rock. Myrtus communis leaves collected from the Shiraz Eram Botanical Garden (Iran) were used in a maceration method.

\section{Experimental procedure}

The laboratory method in this research included preparation and extraction of surfactant from Myrtus communis plant, characterization by FTIR, ${ }^{1} \mathrm{H}$ NMR and TGA techniques, IFT tests and CMC calculations, $\mathrm{pH}$ and conductivity measurements, surfactant adsorption measurements, and finally, core flooding under two scenarios of surfactant and ASP slug injection that are graphically shown in Fig. 2. Each of the steps is explained in detail as follows.

\section{Preparation of the extract, purification of surfactant and its characterization}

The maceration method was used for Myrtus communis leaves extraction. In this method, at each stage, $300 \mathrm{~g}$ of dried plant leaves was soaked in $80 \%$ alcohol for three days at room temperature. The mixture was shaken frequently by the shaker during this time. The clear topical solution was then collected and passed through a filter paper. The resulting solution was concentrated at $50{ }^{\circ} \mathrm{C}$, and then, the sample was completely dried with a desiccator connected to a vacuum pump (Azwanida 2015). The optimization method
Table 3 The used salts characteristics

\begin{tabular}{|c|c|c|c|c|}
\hline Salt & Assay (\%) & $\begin{array}{l}\text { Molecular weight (g/ } \\
\text { gmol) }\end{array}$ & Density $\left(\mathrm{g} / \mathrm{cm}^{3}\right)$ & Water solubility $(\mathrm{g} / \mathrm{L})$ \\
\hline $\mathrm{NaCl}$ & $>99$ & 58.44 & 2.16 & 359 \\
\hline $\mathrm{KCl}$ & $>99$ & 74.55 & 1.98 & $281-567$ \\
\hline $\mathrm{MgCl}_{2}$ & $>99$ & 95.21 & 2.32 & $530-730$ \\
\hline $\mathrm{CaCl}_{2}$ & $>96$ & 110.98 & 2.15 & $600-1524$ \\
\hline $\mathrm{Na}_{2} \mathrm{SO}_{4}$ & $>99$ & 142.04 & 2.66 & $48-427$ \\
\hline $\mathrm{MgSO}_{4}$ & $>98$ & 120.37 & 2.66 & $255-710$ \\
\hline $\mathrm{KI}$ & $>99$ & 166 & 3.123 & $1280-2060$ \\
\hline $\mathrm{K}_{2} \mathrm{SO}_{4}$ & $>99$ & 174.25 & 2.66 & $111-240$ \\
\hline
\end{tabular}
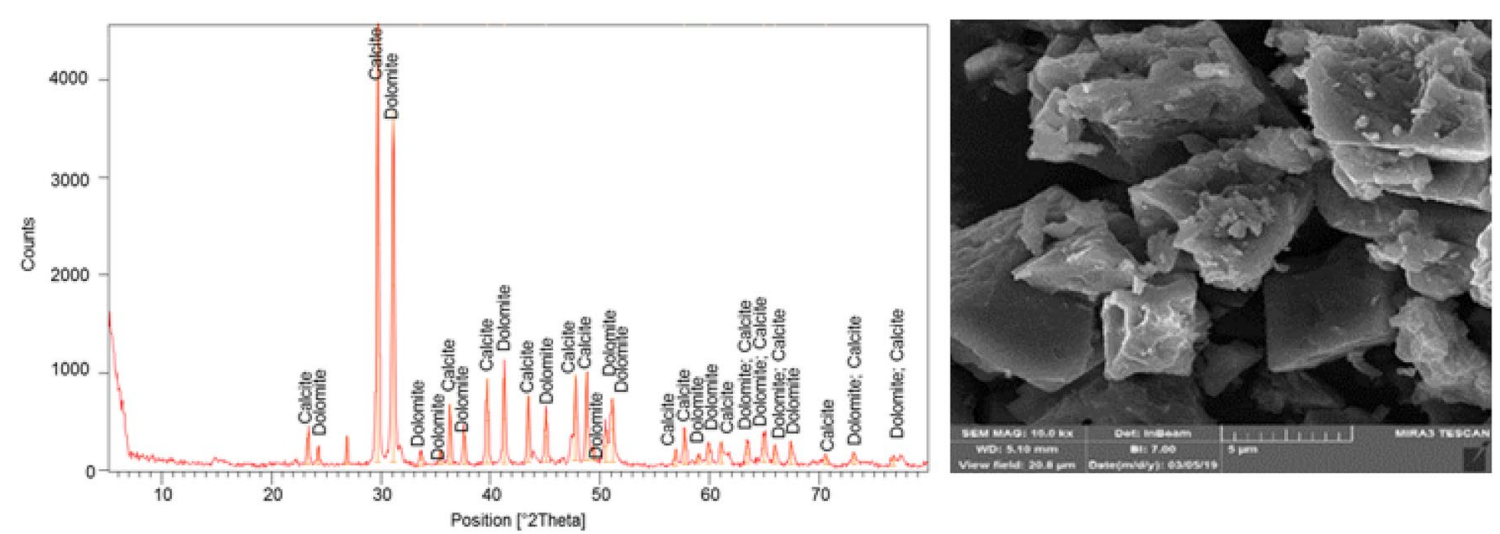

Fig. 1 XRD and SEM analyses of the rock 


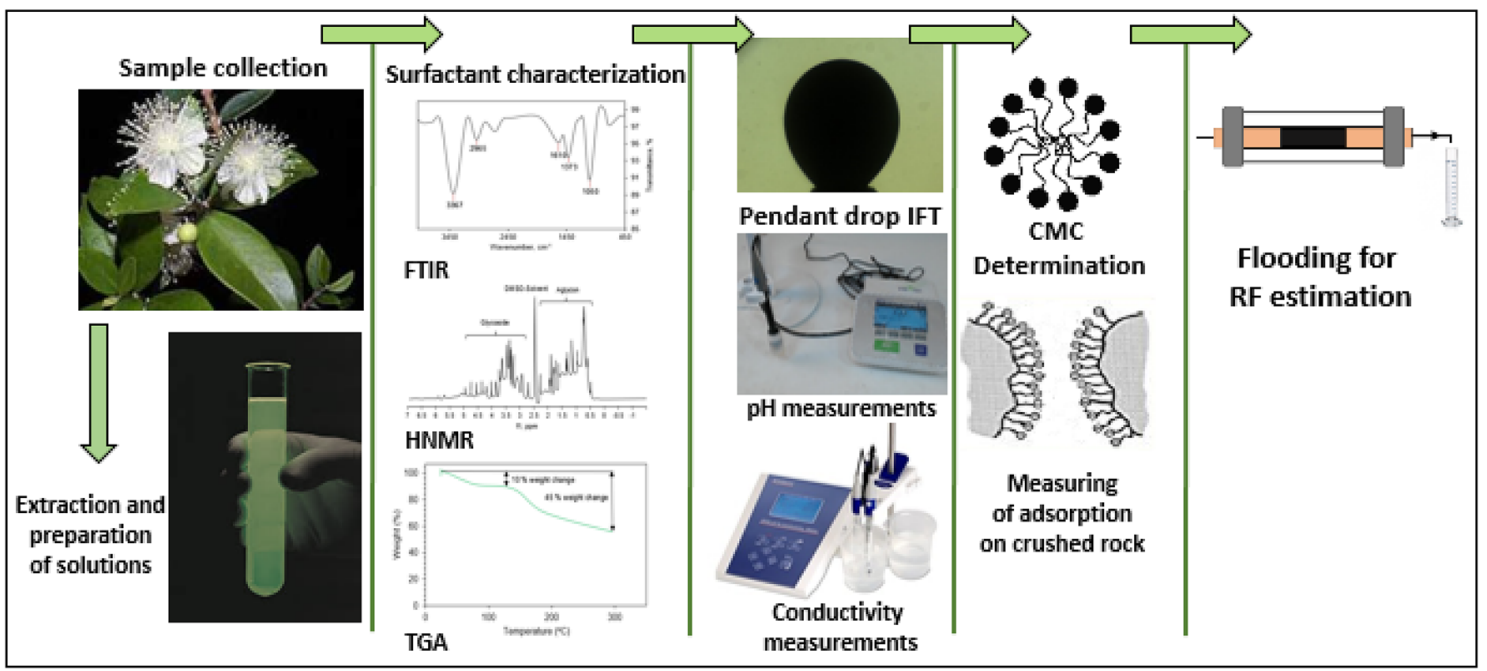

Fig. 2 Laboratory procedures and methods

of Massiot et al. (1992) was then used for saponin purification based on our previous study (Nowrouzi et al. 2020a). The crude material obtained for the purification of saponin was dissolved in distilled water and poured into a separatory funnel. $2.5 \mathrm{ml}$ of water-saturated butanol per $6 \mathrm{~g}$ of primary plant tissue was added and stirred. After a few minutes, two layers containing water and butanol were formed. The layer containing butanol was collected, and the aqueous layer was mixed with the same amount of butanol. The stagnation and separation phase was repeated three times. The three phases containing butanol were mixed. The resulting solution was evaporated and purified at $55^{\circ} \mathrm{C}$. Finally, saponin precipitate was dissolved in methanol, and pure saponin was collected in the same way. FTIR, ${ }^{1} \mathrm{H}$ NMR and TGA techniques were used to characterize and investigate the thermal properties of the surfactant. $\mathrm{KBr}$ was used with the surfactant to obtain IR spectra, and the Tensor 27 FTIR Bruker spectroscopy (Bruker Optik Gmbh, Ettlingen, Germany) recorded the IR spectra. The ${ }^{1} \mathrm{H}$ NMR surfactant spectrum was recorded on a Bruker $500 \mathrm{MHz}$ NMR spectrometer at $25^{\circ} \mathrm{C}$. Thermal properties calculations were performed in a nitrogen atmosphere using Netzsch TG209 F1 analyzer with a heating rate of $10{ }^{\circ} \mathrm{C} / \mathrm{min}$ to $300{ }^{\circ} \mathrm{C}$.

\section{The pH measurement and interfacial tension test}

At first, the pHs of solutions with different concentrations of the surfactant were measured by a $\mathrm{pH}$ Meter manufactured by Mettler Toledo Co., Germany. IFT tests at concentrations of 500, 1000, 2000, 3000, 4000, 5000, 6000 and 7000 ppm and at a temperature of $75^{\circ} \mathrm{C}$ were performed by the IFT400 device described earlier (Manshad et al. 2016, 2017; Najimi et al. 2019; Nowrouzi et al. 2019, 2020a, b). Then, the CMC of surfactant solution was selected and the effects of different salinities of $\mathrm{KCl}, \mathrm{NaCl}, \mathrm{CaCl}_{2}, \mathrm{MgCl}_{2}, \mathrm{Na}_{2} \mathrm{SO}_{4}, \mathrm{MgSO}_{4}$, $\mathrm{K}_{2} \mathrm{SO}_{4}$ and $\mathrm{KI}$ with salt concentrations of 5000, 10,000, $15,000,20,000,30,000,40,000$ and 80,000 ppm were studied at ambient pressure and $75^{\circ} \mathrm{C}$ to find the optimum salinity. To find optimum alkali, $\mathrm{NaOH}$ at different concentrations was added to the solution at CMC of surfactant and the IFT experiments were performed. The IFT400 device was used for performing IFT tests. The device has a sight cell equipped with a metal needle, which is placed on the bottom of the cell during liquid-liquid IFT tests and floated a drop of solution in the air medium. The device software analyzes the drop image and displays the amount of surface tension as output.

\section{Adsorption test}

In the reservoir, some of the surfactants are always wasted due to their adsorption on the surface of the rock. By estimating the amount of adsorption, it can be prevented from reducing its efficiency in the porous medium by injecting water plus adsorbed amount with an equivalent concentration of CMC. To perform the adsorption experiments, $8 \mathrm{~g}$ of carbonate rock and $40 \mathrm{ml}$ of surfactant solutions at 500 , 1000, 2000, 3000, 4000, 5000, 6000 and 7000 ppm were mixed by an orbital batch at $25^{\circ} \mathrm{C}$ and adsorbed amount in the 4-h intervals was measured using a reduction in surfactant concentration until the value of adsorption reached constant or similar values. The change in the surfactant concentration was measured by the conductivity measurement using the conductivity meter, model 3450 , manufactured by Jenway Company, England and the adsorption rate was calculated using Eq. (1) (Zendehboudi et al. 2013). 


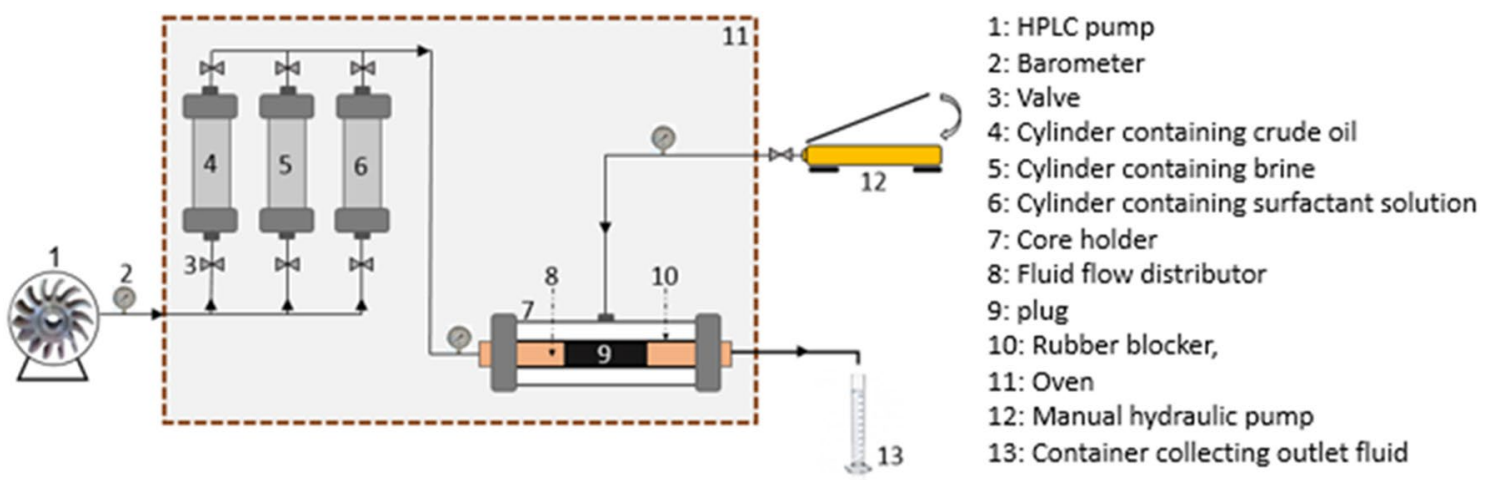

Fig. 3 The schematic of flooding system (Nowrouzi et al. 2020a)

$q=\frac{m_{\text {solution }}\left(C_{0}-C\right)}{m_{\text {carbonate }}} \times 10^{-3}$

where $q$ is the value of adsorbed surfactant in $\mathrm{mg}$ surfactant/g rock, $m_{\text {solution }}$ represents the total mass of the solution in $g, C_{0}$ and $C$ are the primary and secondary concentrations of surfactant in ppm and $m_{\text {carbonate }}$ stands for the mass of carbonate rock particles in $g$.

\section{Core flooding}

Two oil production tests that include the surfactant and ASP slug injection were done after initial experiments of the plugs parameters such as porosity, and permeability. Secondary injection of saline water was performed into the carbonate plugs saturated with oil. The floods were fixed with a flow rate of $0.2 \mathrm{cc} / \mathrm{min}$ at a temperature of $75{ }^{\circ} \mathrm{C}$. Saline water injection was done in the secondary stage. The surfactant flooding was done at CMC and optimum salinity. The ASP slug had a volume of $0.5 \mathrm{PV}$ and contained an optimal concentration of surfactant, alkali and salinity and PHPA polymer with a concentration of $1000 \mathrm{ppm}$. The device of core flooding is according to the schematic of Fig. 3. A pump automatically directs the hydraulic liquid to the back of three pistons. The injection fluid inside the cylinder enters the plug holding chamber and is injected into the plug at a certain rate. The cylinders, which contain oil, brine, and chemical solution, are housed in an oven, along with the core holder. The output fluids are stored in a container for collecting.

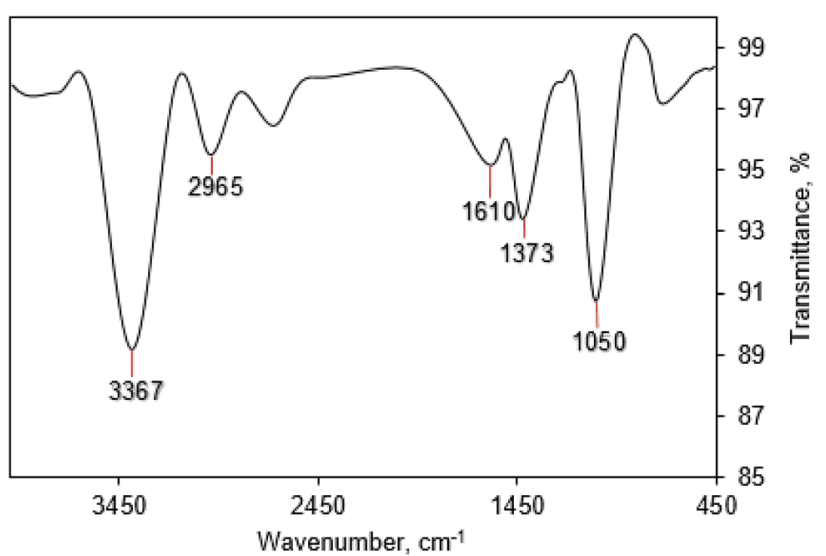

Fig. 4 The analysis of FTIR for the surfactant

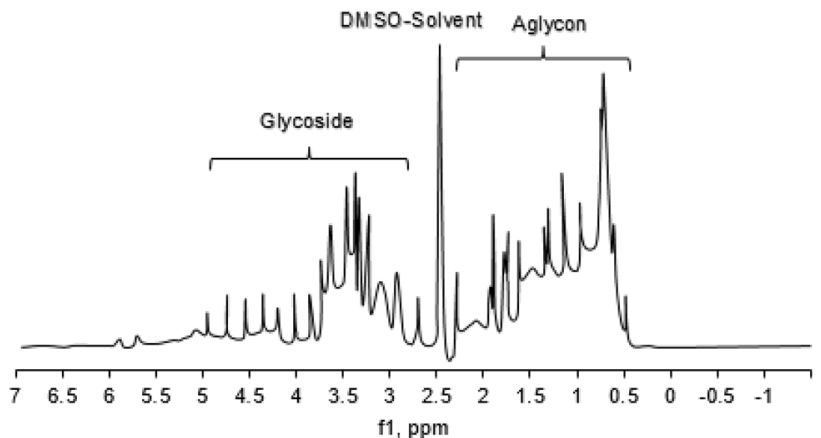

Fig. 5 The analysis of ${ }^{1} \mathrm{H}$ NMR for the surfactant

\section{Results and discussion}

\section{Interpretation of FTIR, ${ }^{1} \mathrm{H}$ NMR, and TGA analyses}

Figure 4 shows FTIR analysis of the surfactant. A peak at $3367 \mathrm{~cm}^{-1}$ indicates the stretching vibration of multiple hydroxyls in the side chain of oligosaccharide of saponin. 


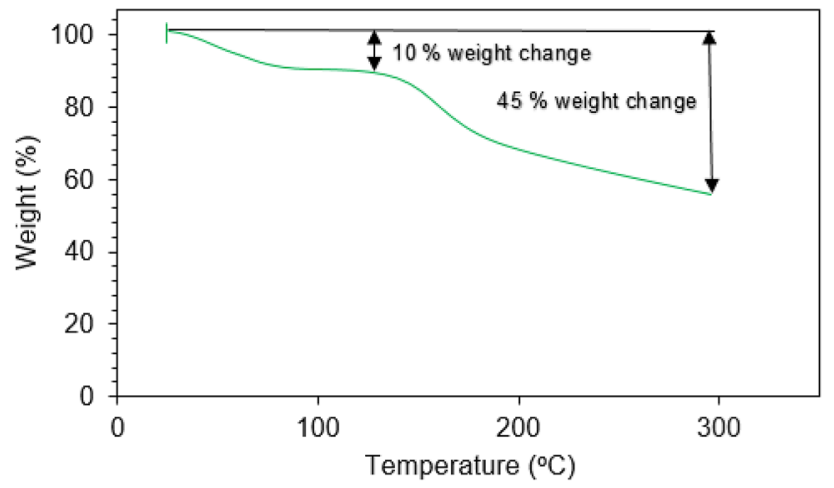

Fig. 6 The analysis of TGA for the surfactant

Table 4 The $\mathrm{pH}$ changes at various concentrations of surfactants
Surfactant concentration $\mathrm{pH}$ (ppm)

\begin{tabular}{ll}
\hline 500 & 5.52 \\
1000 & 5.41 \\
2000 & 5.26 \\
3000 & 5.09 \\
4000 & 4.93 \\
5000 & 4.76 \\
6000 & 4.51 \\
7000 & 4.38 \\
\hline
\end{tabular}

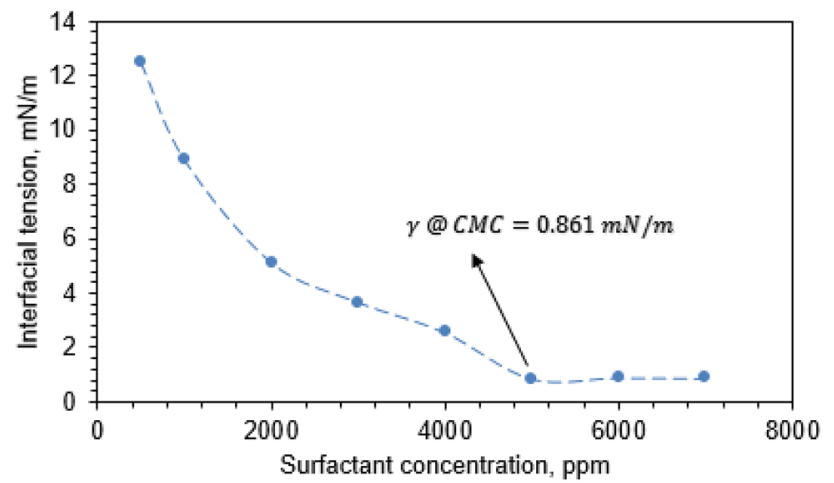

Fig. 7 Water-oil interfacial tension versus surfactant concentration

The peak at $2965 \mathrm{~cm}^{-1}$ is related to the $\mathrm{C}-\mathrm{H}$ aliphatic sapogenin bond, and the peak at $1610 \mathrm{~cm}^{-1}$ represents the $\mathrm{C}=\mathrm{C}$ bond at sapogenin. The peak of $1373 \mathrm{~cm}^{-1}$ indicates the $-\mathrm{OH}$ bond, and finally, the peak at $1050 \mathrm{~cm}^{-1}$ is associated with $\mathrm{C}-\mathrm{O}$ stretching vibration (Wang et al. 2014). Figure 5 shows the ${ }^{1} \mathrm{H}$ NMR analysis. Chemical shifts at $2.8-5.5 \mathrm{ppm}$ mainly show protons in the oligosaccharide portion of saponin, whereas chemical shifts at $1.7-2.35 \mathrm{ppm}$ are mainly related to protons in the agilcone saponin portion (Xiong et al. 2014). Figure 6 shows the TGA analysis. According

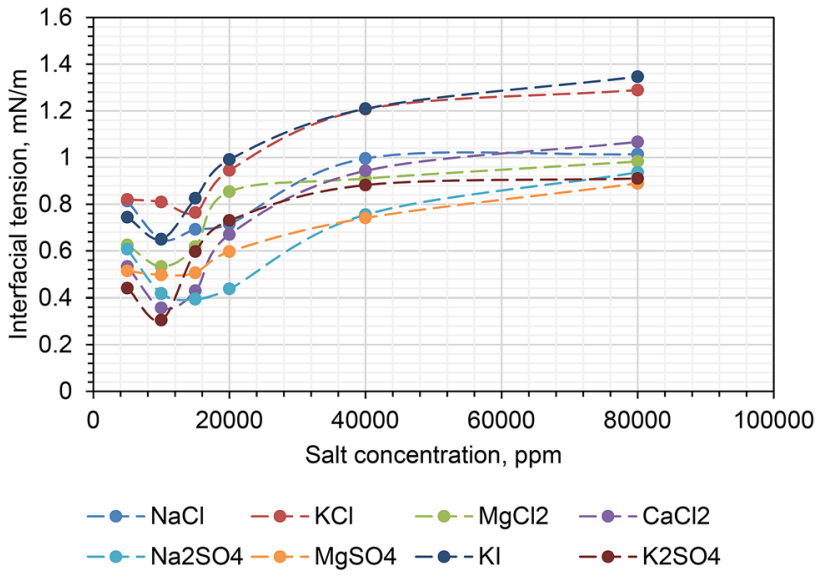

Fig. 8 Different salinity effect on the IFT at CMC

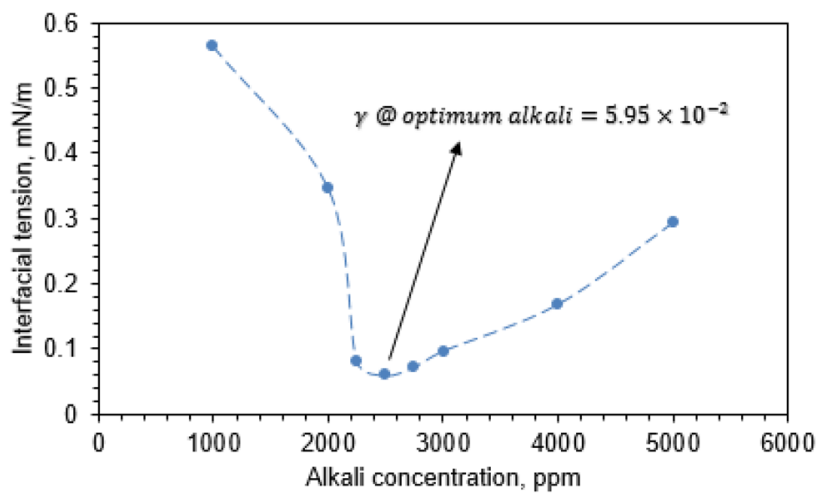

Fig. $9 \mathrm{NaOH}$ alkali effect on the IFT at CMC

to the data in this chart, the initial weight loss reaches about $10 \%$ from 25 to $130^{\circ} \mathrm{C}$. Considering the removal of sample moisture and its resulting weight loss, it can be concluded that Myrtus communis surfactant stability is suitable for reservoir temperatures.

\section{The pH measurement and interfacial tension test results}

The $\mathrm{pH}$ values are reported in Table 4. The range of $\mathrm{pH}$ is between 4 and 6 that are placed in the range of acid and as can be seen by increasing the concentration of surfactant, the value of $\mathrm{pH}$ decreases. Figure 7 shows the IFT values of the pendant oil drop in the aqueous environment system. Surfactants have different effects on injected saline water. Therefore, identifying optimum salinity along with the most useful surfactant concentration, which is normally equivalent to critical micelle concentration (CMC) of surfactant, is necessary. Figure 8 shows the effects of different salinities on the IFT of surfactant solution at CMC and oil. The IFT value is inversely correlated with the surfactant concentration: As 
the concentration increases, the interfacial tension to a certain concentration (or CMC) shows a significant drop. This is a general trend for interfacial tensile behavior against surfactant concentrations and has been observed in previous studies (Pal et al. 2016). The IFT values for surfactant concentrations of 500, 1000, 2000, 3000, 4000, 5000, 6000 and $7000 \mathrm{ppm}$ were abstained 12.498, 8.913, 5.142, 3.679, $2.571,0.861,0.894$ and $0.873 \mathrm{mN} / \mathrm{m}$, respectively. According to Fig. 8, the IFT values of the surfactant at CMC and oil at the optimum salinity of each saline water are as follows: $\mathrm{NaCl}$, at a concentration of $10,000 \mathrm{ppm}, 0.649 \mathrm{mN} / \mathrm{m}, \mathrm{KCl}$, at a concentration of $15,000 \mathrm{ppm}, 0.764 \mathrm{mN} / \mathrm{m}, \mathrm{CaCl}_{2}$, at a concentration of $10,000 \mathrm{ppm}, 0.357 \mathrm{mN} / \mathrm{m}, \mathrm{MgCl}_{2}$, at a concentration of $10,000 \mathrm{ppm}, 0.533 \mathrm{mN} / \mathrm{m}, \mathrm{K}_{2} \mathrm{SO}_{4}$, at a concentration of $10,000 \mathrm{ppm}, 0.305 \mathrm{mN} / \mathrm{m}, \mathrm{Na}_{2} \mathrm{SO}_{4}$, at a concentration of $15,000 \mathrm{ppm}, 0.394 \mathrm{mN} / \mathrm{m}, \mathrm{MgSO}_{4}$, at a concentration of $10,000 \mathrm{ppm}, 0.497 \mathrm{mN} / \mathrm{m}$ and $\mathrm{KI}$, at a concentration of $10,000 \mathrm{ppm}, 0.650 \mathrm{mN} / \mathrm{m}$. Therefore, the greatest decrease in IFT occurred in the presence of soluble ions of $\mathrm{K}_{2} \mathrm{SO}_{4}$ salt at a concentration of $10,000 \mathrm{ppm}$. This optimal salinity was selected for flooding. Figure 9 shows the $\mathrm{NaOH}$ alkali effect on IFT at CMC. IFT value at a concentration of $2500 \mathrm{ppm}$ is minimal. At this point, the IFT has a value of $0.059 \mathrm{mN} / \mathrm{m}$. The reason for the IFT change in the presence of ions also depends on the adsorption of ions on the interface due to the presence of some polar compounds in the oil such as asphaltene and resin. Asphaltene and resin are natural surfactants in crude oil, and due to the difference in charge with ions, they tend to adsorb them and form complexes at the interface. This tendency is not the same for different ions. For example, the $\mathrm{Mg}^{2+}$ desire to resin molecules is higher than $\mathrm{Ca}^{2+}$, while $\mathrm{Ca}^{2+}$ dependence on asphaltene molecules is higher than $\mathrm{Mg}^{2+}$ (Lashkarbolooki et al. 2014; Nowrouzi et al. 2019). In addition, at lower concentrations due to the salt-in effect, there is lower IFT due to the salt-in effect (Yi et al. 2014; Armenante and Karlsson 1982; Standal et al. 1999). When two immiscible fluids collide are at the same surface, chemical and physical reactions occur between the

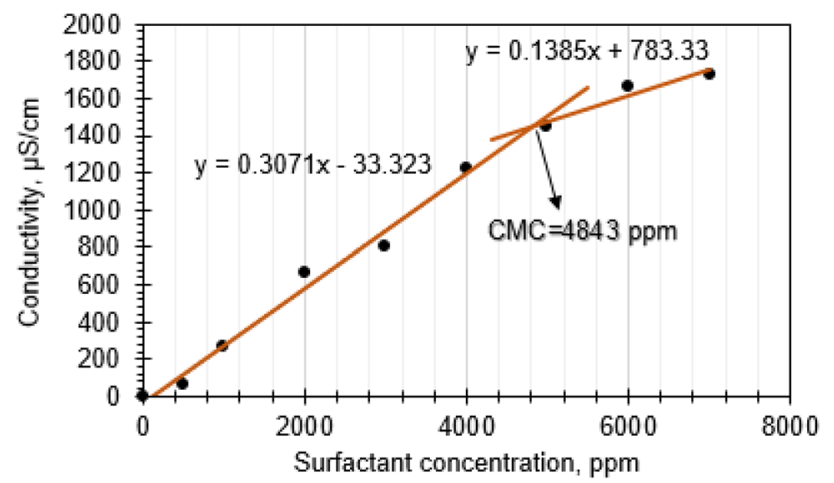

Fig. 10 Conductivity values of the surfactant solution

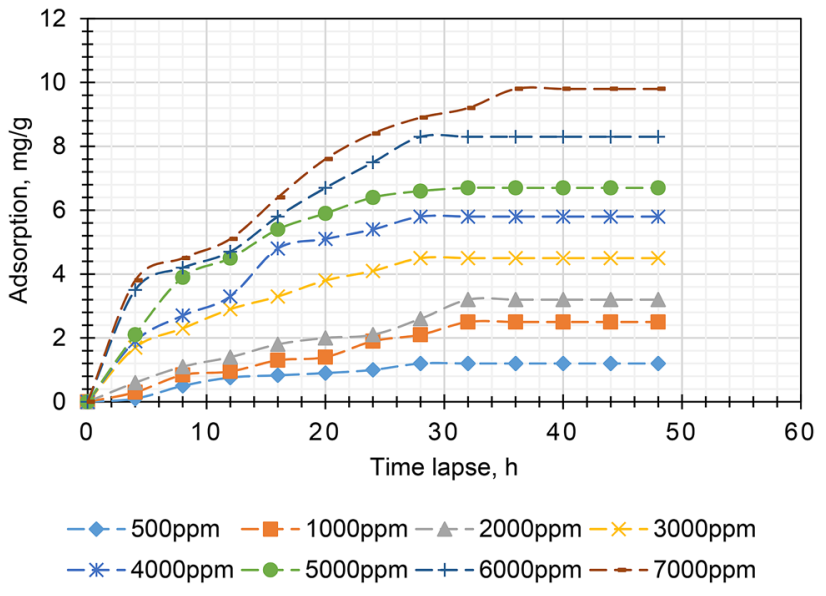

Fig. 11 Natural surfactant adsorption rates on carbonate rocks at various concentrations

molecules located in the interface. When a surfactant is present in the system, a mechanism similar to the water-air interface occurs in the water-oil interface. Surfactant molecules fall into the same phase as the hydrophobic part in the oil phase and the hydrophilic part in the aqueous phase. As a result, a thin film of surfactant molecules is formed in the interface, causing less interfacial tension than before. In the presence of alkali, the interfacial tension is reduced more than the surfactant solution. This behavior can be attributed to the carboxylic acid ionization in the presence of alkali and the production of the in situ petroleum soap as a result of presence of the alkali and acidic components in the oil (Dehghan et al. 2017).

\section{Adsorption test results}

Figure 10 shows the conductivity of the surfactant solutions and Fig. 11 indicates its adsorption rates on crushed carbonate rocks at $25^{\circ} \mathrm{C}$ and atmospheric pressure. As mentioned earlier, CMC was obtained from two methods of measuring interfacial tension and conductivity of surfactant solutions. By using Fig. 10, the collision point of two regression lines in the conductivity curve will be equal to the CMC value which is $4843 \mathrm{ppm}$. This value was obtained by the interfacial tension method considering the behavior of the surfactant solution with a change in interfacial tension at $5000 \mathrm{ppm}$, which is very small. The reason for this insignificant difference could be how the method works in the estimation of CMC because the choice of surfactant concentrations is such that CMC in the interfacial tension method is one of the round concentrations selected in the test, but in the covalent method, the CMC coordinates are obtained from the solution of the two variable equations, which are related to the regression lines and can be in a concentration

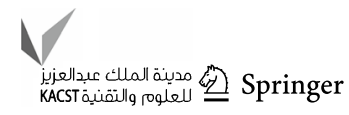


equal to the limits of the selected concentrations in the experiments.

The adsorption values calculated in the 4-h intervals show that as the surfactant concentration increases, adsorption increases, but at each concentration, over time, a stable value is reached, after which no other surfactant is adsorbed on the surface of the rock. Accordingly, the lowest adsorption concentration resulted at $500 \mathrm{ppm}$ and the highest adsorption rate resulted at a concentration of $7000 \mathrm{ppm}$.

Surfactant adsorption is a process of transferring surfactant molecules from the liquid to the surface and depends on the structure and properties of surfactant and surface (Dabiri and Honarvar 2020). Many mechanisms have a role in the adsorption of surfactants on the rock surface (Rosen and Kunjappu 2012). The majority of these mechanisms include hydrophobic bonding, ion-pairing, ion exchange, adsorption by the polarization of $\pi$ electrons and adsorption by dispersion forces (Griffith and Alexander 1967). With this in mind, the adsorption of surfactants may be chemical, physical, and electrostatic. The adsorption of non-ionic surfactants, as used in this study, is generally a physical adsorption type. This means that they are different from many other surfactants, and very little change in temperature, concentration, and molecular structure can affect adsorption. This is due to the adsorbate-adsorbate and adsorbate-solvent mechanism which results in the formation of surfactant accumulation in the solution that leads to a change in surfactant orientation in the surface (Dabiri and Honarvar 2020; Parfitt and Rochester 1983). It is believed that non-ionic surfactants are adsorbed physically rather than chemically except for possible hydrogen bonding with hydroxyl groups on the surface. Most non-ionic surfactants contain polar groups that can form hydrogen bonds with surface hydroxyls rendering the surface hydrophobic. (Bulatovic 2007). These functional groups are present in the reservoir due to the presence of the oil components on the surface of the reservoir rock.

\section{Core flooding test results}

As mentioned earlier, two flooding tests were performed including surfactant injection at CMC and optimum salinity and ASP slug injection. Table 5 shows the carbonate plugs properties. Figure 12 shows the oil recovery curve versus injected fluids in the processes of surfactant and ASP injection. According to the surfactant injection curve, the oil recovery in the second stage of saline water injection (1.5 $\mathrm{PV}$ ) was $41.8 \%$. Oil production at this part was fixed after

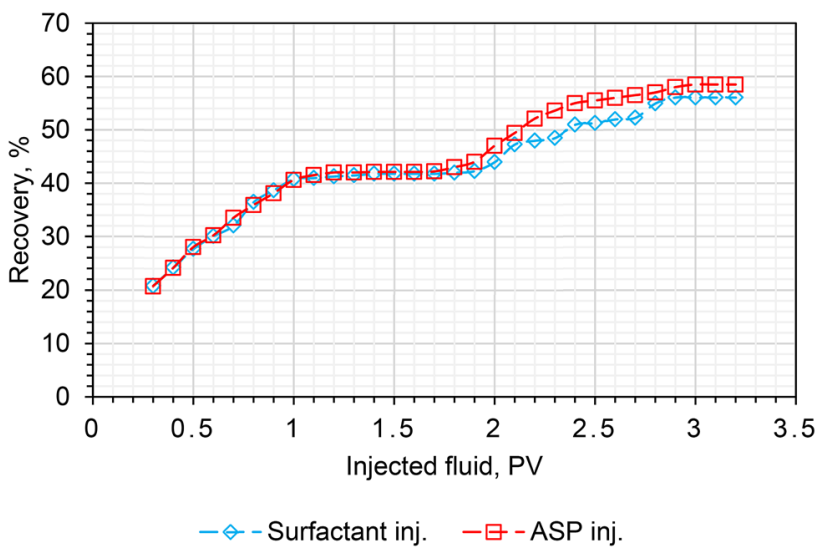

Fig. 12 Oil recovery by surfactant and ASP slug injection

1.4 PV injection and then no oil was recovered. The surfactant injection was then continued until the total volume of 3.2 PV (1.7 PV of surfactant) fluid was injected to obtain a final production and oil recovery. The final recovery coefficient obtained from the secondary injection of saline water and tertiary surfactant injection was $56.1 \%$, of which $14.3 \%$ was the share of the surfactant injection. Oil recovery in the tertiary injection began after injection of a total volume of $1.8 \mathrm{PV}$, i.e., $0.3 \mathrm{PV}$ of the surfactant, and ended by injection of a total fluid of 2.9 PV, i.e., 1.4 PV of the surfactant. In the injection of 0.5 PV ASP slug, the secondary recovery from brine injection was $42.1 \%$. Tertiary oil production resumes after $0.2 \mathrm{PV}$ injection of ASP solution at optimum salinity. The final oil recovery was $58.5 \%$ of which $16.4 \%$ was obtained by tertiary injection. According to these interpretations, ASP injection results in a $2.1 \%$ higher recovery than the surfactant injection. This means that the use of small amounts of alkali and polymer can dramatically reduce the amount of surfactant needed for a flooding operation and in addition to more recovery. A set of parameters enhances oil recovery in surfactant and ASP slug flooding. In secondary saline water injection, most of the oil recovery is sweep efficiency while the mechanism of interfacial tension reduction plays a more important role in surfactant flooding. Capillary pressure is an important property that directly and indirectly influences parameters such as relative permeability. This pressure is defined by Eq. (2). When oil droplets are trapped in the reservoir cavity, due to the very small cross section of these cavities, and according to Eq. (2), the capillary pressure on both sides of the cavity becomes very high and the water pressure cannot overcome it. IFT reduction

Table 5 Plugs properties

\begin{tabular}{lllllll}
\hline Plug no & Perm. (md) & Por. $(\%)$ & $L(\mathrm{~cm})$ & Total $V_{\mathrm{P}}\left(\mathrm{cm}^{3}\right)$ & $S_{\mathrm{wi}}(\%)$ & OOIP $\left(\mathrm{cm}^{3}\right)$ \\
\hline 1 & 9.42 & 19.36 & 7.4 & 16.3251 & 24 & 12.0 \\
2 & 8.9 & 20.01 & 7.2 & 16.4172 & 21 & 12.8 \\
\hline
\end{tabular}


will reduce it and the trapped oil is mobilized in the cavities (Green and Willhite 1998).

$P_{\mathrm{c}}=\frac{2 \gamma \cos \theta}{r}$

where $P_{\mathrm{c}}$ is the capillary pressure, $\mathrm{r}$ represents the capillary radius, $\gamma$ stands for IFT and $\theta$ is contact angle.

In addition to the surfactant injection mechanism, ASP slug injection increases the viscosity of injection fluid and improves the mobility ratio.

\section{Conclusion and recommendation}

The saponin extracted from Myrtus communis as a natural surfactant was characterized and used for chemical water injection into carbonate plugs. The most important conclusions are as follows:

- Myrtus communis natural surfactant has a great ability in the interfacial tension reduction so that IFT value of $0.861 \mathrm{mN} / \mathrm{m}$ is obtained at surfactant CMC which also reaches an ultra-low value of $5.95 \times 10^{-2}$ at optimum salinities and alkali that is suitable for EOR.

- The obtained CMC values show a low concentration. Based on the interfacial tension value, this natural surfactant, in contrast to most of reported natural surfactants, is effective at low concentrations.

- The adsorption of Myrtus communis surfactant on the carbonate rock surface increases by increasing concentration, and after a given time, it becomes constant at more concentrations and then the final adsorption rate is fixed.

- The surfactant flooding increases the oil recovery by $14.3 \%$ and injection of a small volume of ASP containing $\mathrm{NaOH}$ alkali and PHPA polymer increases the oil recovery by $16.4 \%$.

The adsorption experiments were done here using crushed rock samples. This method, although is common, due to an increase in the surface of rock resulting from crushing, cannot well represent the surface of the porous medium. Therefore, it is suggested that this study be continued with the flooding of surfactant solutions in the plug and the calculation of adsorption in the porous media.

Funding There is no funding statement.

\section{Declarations}

Conflict of interest On behalf of all the co-authors, the corresponding author states that there is no conflict of interest.
Open Access This article is licensed under a Creative Commons Attribution 4.0 International License, which permits use, sharing, adaptation, distribution and reproduction in any medium or format, as long as you give appropriate credit to the original author(s) and the source, provide a link to the Creative Commons licence, and indicate if changes were made. The images or other third party material in this article are included in the article's Creative Commons licence, unless indicated otherwise in a credit line to the material. If material is not included in the article's Creative Commons licence and your intended use is not permitted by statutory regulation or exceeds the permitted use, you will need to obtain permission directly from the copyright holder. To view a copy of this licence, visit http://creativecommons.org/licenses/by/4.0/.

\section{References}

Alsabagh AM, Aboulrous AA, Abdelhamid MM, Mahmoud T, Haddad AS, Rafati R (2021) Improvement of heavy oil recovery by nonionic surfactant/alcohol flooding in light of the alkane carbon number and interfacial tension properties. ACS Omega 6(29):18668-18683

Armenante PM, Karlsson HT (1982) Salting-out parameters for organic acids. J Chem Eng Data 27(2):155-156

Azwanida NN (2015) A review on the extraction methods use in medicinal plants, principle, strength and limitation. Med Aromat Plants 4(196):2167-0412

Bachari Z, Isari AA, Mahmoudi H, Moradi S, Mahvelati EH (2019) Application of natural surfactants for enhanced oil recovery-critical review. In: IOP conference series: earth and environmental science, vol 221, no 1. IOP Publishing, p 012039

Bulatovic SM (2007) Handbook of flotation reagents: chemistry, theory and practice: volume 1: flotation of sulfide ores. Elsevier, Amsterdam

Dabiri A, Honarvar B (2020) Investigation of interfacial tension reduction, wettability alteration, and oil recovery using a new non-ionic oil-based surfactant from gemini surfactants family coupled with low-salinity water: experimental study on oil-wet carbonate rock. J Surfactants Deterg 23(4):821-829

Dehghan AA, Jadaly A, Ayatollahi S, Masihi M (2017) Acidic heavy oil recovery using a new formulated surfactant accompanying alkali-polymer in high salinity brines. J Surfactants Deterg 20(3):725-733

Ganie K, Manan MA, Ibrahim A, Idris AK (2019) An experimental approach to formulate lignin-based surfactant for enhanced oil recovery. Int J Chem Eng 2019:4120859

Ghannadi A, Dezfuly N (2011) Essential oil analysis of the leaves of Persian true myrtle. Int J Med Aroma Plants 1(2):48-50

Green DW, Willhite GP (1998) Enhanced oil recovery, vol 6. Henry L. Doherty Memorial Fund of AIME, Society of Petroleum Engineers, Richardson, pp 143-154

Griffith JC, Alexander AE (1967) Equilibrium adsorption isotherms for wool/detergent systems: I. The adsorption of sodium dodecyl sulfate by wool. J Colloid Interface Sci 25(3):311-316

Khayati H, Moslemizadeh A, Shahbazi K, Moraveji MK, Riazi SH (2020) An experimental investigation on the use of saponin as a non-ionic surfactant for chemical enhanced oil recovery (EOR) in sandstone and carbonate oil reservoirs: IFT, wettability alteration, and oil recovery. Chem Eng Res Des 160:417-425

Kiani S, Rogers SE, Sagisaka M, Alexander S, Barron AR (2019) A new class of low surface energy anionic surfactant for enhanced oil recovery (EOR). Energy Fuels 33(4):3162-3175

Kumar A, Mandal A (2018) Characterization of rock-fluid and fluid-fluid interactions in presence of a family of synthesized

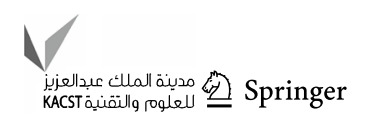


zwitterionic surfactants for application in enhanced oil recovery. Colloids Surf A 549:1-12

Lashkarbolooki M, Ayatollahi S, Riazi M (2014) The impacts of aqueous ions on interfacial tension and wettability of an asphaltenic-acidic crude oil reservoir during smart water injection. J Chem Eng Data 59(11):3624-3634

Madani M, Zargar G, Takassi MA, Daryasafar A, Wood DA, Zhang Z (2019) Fundamental investigation of an environmentallyfriendly surfactant agent for chemical enhanced oil recovery. Fuel 238:186-197

Majidaie S, Mushtaq M, Tan IM, Demiral B, Lee SY (2012) Nonpetrochemical surfactant for enhanced oil recovery. Paper presented at the SPE EOR Conference at Oil and Gas West Asia, Muscat, Oman, SPE-153493-MS

Manshad AK, Olad M, Taghipour SA, Nowrouzi I, Mohammadi AH (2016) Effects of water soluble ions on interfacial tension (IFT) between oil and brine in smart and carbonated smart water injection process in oil reservoirs. J Mol Liq 223:987-993

Manshad AK, Rezaei M, Moradi S, Nowrouzi I, Mohammadi AH (2017) Wettability alteration and interfacial tension (IFT) reduction in enhanced oil recovery (EOR) process by ionic liquid flooding. J Mol Liq 248:153-162

Massiot G, Lavaud C, Benkhaled M, Le Men-Olivier L (1992) Soyasaponin VI, a new maltol conjugate from alfalfa and soybean. J Nat Prod 55(9):1339-1342

Najimi S, Nowrouzi I, Manshad AK, Farsangi MH, Hezave AZ, Ali JA, Keshavarz A, Mohammadi AH (2019) Investigating the effect of [C $8 \mathrm{Py}][\mathrm{Cl}]$ and $[\mathrm{C} 18 \mathrm{Py}][\mathrm{Cl}]$ ionic liquids on the water/oil interfacial tension by considering Taguchi method. J Pet Explor Product Technol 9(4):2933-2941

Nguyen TT, Morgan C, Poindexter L, Fernandez J (2019) Application of the hydrophilic-lipophilic deviation concept to surfactant characterization and surfactant selection for enhanced oil recovery. J Surfactants Deterg 22(5):983-999

Nowrouzi I, Manshad AK, Mohammadi AH (2019) Effects of dissolved carbon dioxide and ions in water on the dynamic interfacial tension of water and oil in the process of carbonated smart water injection into oil reservoirs. Fuel 243:569-578

Nowrouzi I, Mohammadi AH, Manshad AK (2020a) Water-oil interfacial tension (IFT) reduction and wettability alteration in surfactant flooding process using extracted saponin from Anabasis Setifera plant. J Pet Sci Eng 189:106901

Nowrouzi I, Mohammadi AH, Manshad AK (2020b) Effect of a synthesized anionic fluorinated surfactant on wettability alteration for chemical treatment of near-wellbore zone in carbonate gas condensate reservoirs. Pet Sci 17(6):1655-1668

Pal N, Babu K, Mandal A (2016) Surface tension, dynamic light scattering and rheological studies of a new polymeric surfactant for application in enhanced oil recovery. J Pet Sci Eng 146:591-600

Pal N, Kumar N, Verma A, Ojha K, Mandal A (2018a) Performance evaluation of novel sunflower oil-based Gemini surfactant (s) with different spacer lengths: application in enhanced oil recovery. Energy Fuels 32(11):11344-11361

Pal N, Saxena N, Mandal A (2018b) Studies on the physicochemical properties of synthesized tailor-made Gemini surfactants for application in enhanced oil recovery. J Mol Liq 258:211-224

Pal N, Saxena N, Laxmi KD, Mandal A (2018c) Interfacial behaviour, wettability alteration and emulsification characteristics of a novel surfactant: Implications for enhanced oil recovery. Chem Eng Sci 187:200-212

Pal N, Samanta K, Mandal A (2019) A novel family of non-ionic Gemini surfactants derived from sunflower oil: Synthesis, characterization and physicochemical evaluation. J Mol Liq 275:638-653

Parfitt GD, Rochester CH (1983) Adsorption from solution at the solid/ liquid interface. Academic Press, London

Pillai P, Kumar A, Mandal A (2018) Mechanistic studies of enhanced oil recovery by imidazolium-based ionic liquids as novel surfactants. J Ind Eng Chem 63:262-274

Pu WF, Du DJ, Tang YL, Wang S (2018) Synthesis of an alkyl polyoxyethylene ether sulfonate surfactant and its application in surfactant flooding. J Surfactants Deterg 21(5):687-697

Rosen MJ, Kunjappu JT (2012) Surfactants and interfacial phenomena. Wiley, Hoboken

Rostami A, Hashemi A, Takassi MA, Zadehnazari A (2017) Experimental assessment of a lysine derivative surfactant for enhanced oil recovery in carbonate rocks: mechanistic and core displacement analysis. J Mol Liq 232:310-318

Saxena N, Goswami A, Dhodapkar PK, Nihalani MC, Mandal A (2019a) Bio-based surfactant for enhanced oil recovery: Interfacial properties, emulsification and rock-fluid interactions. J Pet Sci Eng 176:299-311

Saxena N, Saxena A, Mandal A (2019b) Synthesis, characterization and enhanced oil recovery potential analysis through simulation of a natural anionic surfactant. J Mol Liq 282:545-556

Standal SH, Blokhus AM, Haavik J, Skauge A, Barth T (1999) Partition coefficients and interfacial activity for polar components in oil/water model systems. J Colloid Interface Sci 212(1):33-41

Tay A, Mouret A, Mascle M (2019) Internal ketone sulfonate: a new bio-sourced surfactant for chemical EOR in Sea Water. In Offshore Technology Conference. Offshore technology conference. OTC-29575-MS

Wang C, Chao Z, Sun W, Wu X, Ito Y (2014) Isolation of five glycosides from the barks of Ilex rotunda by high-speed countercurrent chromatography. J Liq Chromatogr Relat Technol 37(16):2363-2376

Xiong H, Ding X, Yang XZ, Yang GZ, Mei ZN (2014) Triterpene saponins from the stems of Entada phaseoloides. Planta Med 80(8-9):710-718

Yan L, Ma J, Cui Z, Jiang J, Song B, Pei X (2019) A new series of double-chain single-head sulfobetaine surfactants derived from 1, 3-dialkyl glyceryl ether for reducing crude oil/water interfacial tension. J Surfactants Deterg 22(1):47-60

Yi C, Xie S, Qiu X (2014) Salting-out effect of dipotassium hydrogen phosphate on the recovery of acetone, butanol, and ethanol from a prefractionator. J Chem Eng Data 59(5):1507-1514

Zendehboudi S, Ahmadi MA, Rajabzadeh AR, Mahinpey N, Chatzis I (2013) Experimental study on adsorption of a new surfactant onto carbonate reservoir samples-application to EOR. Can J Chem Eng 91(8):1439-1449

Publisher's Note Springer Nature remains neutral with regard to jurisdictional claims in published maps and institutional affiliations. 